\title{
ЯЗЫКОВАЯ И РЕЧЕВАЯ БИОГРАФИЯ КАК ОДИН ИЗ ФАКТОРОВ ФОРМИРОВАНИЯ ЯЗЫКОВОЙ ЛИЧНОСТИ И ЕЕ МЕНТАЛЬНОГО ЛЕКСИКОНА
}

\section{Лямзина С.А.}

Статья посвящена изучению особенностей организачии ментального лексикона языковой личности. В связи с чем основной исследовательский вопрос сформулирован следующим образом: сущеествуют ли устойчивые корреляции между языковой / речевой биографией человека и характеристиками системных связей слов в его ментальном лексиконе?

Цель данной статьи - сформулировать на основе проводимого исследования ряд аргументов в пользу обоснованности гипотезы о том, что одним из факторов, влияющих на речевую продукцию индивида (его языковую личность), а, следовательно, на структуру и содержание его ментального лексикона, является языковая и речевая биография.

Основные методы, используемыле в исследовании: метод структурированного интервью, элементы качественно-количественных подсчетов и описательный метод.

Результаты. Проведенное исследование выявило, что языковая и речевая биография является одним из факторов, влияющих на речевую продукиию человека (его языковую личность), а поскольку вербально-семантический уровень языковой личности представлен в ментальном лексиконе, то его структура и содержание также зависят от речевой и языковой биографии. Следовательно, знания языковой и речевой биографии помогают определить, какие слова могут находиться в ядре ментального лексикона.

Область применения результатов. Полученнье результаты важно учитывать при реабилитащии пациентов с нарушением речи, 
которое возникает при органических поражениях мозга - афазиях, поскольку это дает возможность разработать для них индивидуальный комплекс упражнений, принимающий во внимание особенности их языковой личности и языковой / речевой биографии.

Ключевые слова: языковая личность; ментальный лексикон; структура ментального лексикона; содержание ментального лексикона; языковая биография; речевая биография.

\section{LANGUAGE AND SPEECH BIOGRAPHY AS ONE OF THE FACTORS FORMING A LANGUAGE PERSONALITY AND MENTAL LEXICON}

\section{Lyamzina S.A.}

The article is devoted to the study of the organization of the mental lexicon of a language personality. This research focuses on finding answers to the questions: are there stable correlations between a person's language / speech biography and the characteristics of the systemic connections of words in his or her mental lexicon?

Purpose. The aim of this article is to present a number of arguments in favor of the validity of the hypothesis that one of the factors affecting the speech production of an individual (his or her language personality), and, consequently, the structure and content of the mental lexicon, is language and speech biography.

Methodology. The main methods used in the study include a structured interview method, elements of qualitative-quantitative calculations and a descriptive method.

Results. It was found out that language and speech biography is one of the factors affecting a person's speech production (his or her language personality), and since the verbal-semantic level of a language personality is represented in the mental lexicon, its structure and content also depend on speech and language biography.

Therefore, knowledge of language and speech biography helps to determine what words can be in the core of the mental lexicon. 
Practical implications. It is important to consider the obtained results during the rehabilitation of patients with aphasia - a speech disorder, since it will help to create an individual set of exercises for such patients, taking into account the characteristics of their language personality and language / speech biography.

Keywords: language personality; mental lexicon; structure of the mental lexicon; content of the mental lexicon; language biography; speech biography.

Проводимое нами исследование посвящено изучению особенностей организации ментального лексикона. Основной исследовательский вопрос, который находится в фокусе внимания, может быть сформулирован следующим образом: существуют ли устойчивые корреляции между языковой / речевой биографией человека и характеристиками системных связей слов в его ментальном лексиконе?

В фокусе данной публикации находятся ключевые для работы понятия языковой личности, ментального лексикона, языковой и речевой биографии, которые, как показал анализ научной литературы, только находятся в стадии обретения своих сущностных характеристик в рамках антропоцентрической лингвистики.

Цель данной публикации - сформулировать на основе проводимого исследования ряд аргументов в пользу обоснованности гипотезы о том, что одним из факторов, влияющих на речевую продукцию индивида (его языковую личность), а, следовательно, на структуру и содержание его ментального лексикона, является языковая и речевая биография.

\section{Материал и методы}

Материалом исследования послужили: 1) 20 часов аудиозаписей интервью с носителями русского языка; 2) корпус скриптов интервью объемом 20203 слова.

В работе использовались следующие методы: метод структурированного интервью, элементы качественно-количественных подсчетов и описательный метод. 


\section{Основная часть статьи}

$\mathrm{XX}$ в. ознаменовался активным развитием антропоцентрического направления в лингвистике. Усиление роли «человеческого фактора» привело к перемещению фокуса усилий исследователей с проблем описания языковой структуры в область, центром которой становится человек говорящий. Теория языковой личности становится одной из основ современной отечественной лингвистики.

Наиболее подробно теория языковой личности разработана в трудах Ю.Н. Караулова. Под языковой личностью исследователь понимает «совокупность способностей и характеристик человека, обусловливающих создание и восприятие им речевых произведений (текстов), которые различаются а) степенью структурно-языковой сложности, б) глубиной и точностью отражения действительности, в) определенной целевой направленностью» [10, с. 3].

В модели, предложенной Ю.Н. Карауловым, языковая личность состоит из трех уровней: вербально-семантического, когнитивного и прагматического [9]. Иными словами, языковая личность является многогранной, и ее отдельные аспекты проявляются в языковом, речевом и коммуникативном планах.

Последующие исследования других лингвистов направлены на переосмысление и уточнение структуры, предложенной Ю.Н. Карауловым [11].

Следует отметить, что вербально-семантический уровень языковой личности хранится в ментальном лексиконе, поскольку как отмечают некоторые исследователи, он представляет собой своеобразный «резервуар», т. е. часть нашей долговременной памяти, в которой мы храним знания обо всех известных нам словах из знакомых языков [12, с. 381-389].

В свою очередь, как отмечает А.А. Залевская, ментальный лексикон обладает «теми же свойствами, какие специфичны для речевой организации в целом, т. е. он должен пониматься не как пассивное хранилище сведений о языке, а как динамическая функциональная система, самоорганизующаяся вследствие постоянно- 
го взаимодействия между процессом переработки и упорядочения речевого опыта и его продуктами...» [6, с. 154].

Что касается структуры ментального лексикона, то А.А. Залевская и Н.О. Золотова представляют ментальный лексикон как глобальное ассоциативное поле с центральной частью, которая имеет множество связей, разрежающихся по направлению к периферии. Центральная часть представляет собой ограниченное количество единиц, обладающих максимальной ассоциативной силой, которую называют «ядром» [5; 7].

Структурированные в пространстве ядра поля являются способом существования наиболее значимых для человека понятий, связь с которыми позволяет определить максимальную вероятность воспроизведения единиц ядра в случае свободного ассоциирования. В свою очередь, «образ мира», который актуализируется в ядре лексикона, отражает так называемый «наивный реализм» индивида, каждый день оперирующего житейскими (обыденными) понятиями, зафиксированными единицами ядра. Таким образом, в ядре ментального лексикона концентрируются актуальные как для человека, так и для культуры образы действительности в их взаимосвязях и отношениях [7].

Что касается функции ментального лексикона, то он выполняет роль единой информационной базы человека, в которую входят энциклопедические, языковые знания, эмоциональные впечатления и выработанная социумом система норм и оценок данных знаний [15].

Таким образом, можно сделать вывод о том, что ментальный лексикон представляет собой сложное лингвокогнитивное образование, которое модифицирует лексическую систему языка в сознании, отражает окружающую действительность и познавательные процессы языковой личности, а также обеспечивает ее речевые процессы.

Несмотря на активное изучение языковой личности, ряд фактов, касающихся данного понятия, остается малоизученным. В частности, то, что одним из факторов, влияющих на формирование языковой личности, является языковая и речевая биография человека. 
Так, проанализировав ряд источников, мы пришли к выводам, что «языковая биография» - это история становления языковой личности (часто билингвальной или полилингвальной) от этапа зарождения индивидуальной жизни до ее конца в тесном переплетении с процессами приобретения, становления и эволюции когнитивного опыта, с мировоззрением, системой ценностей человека [13, с. 226].

Данное понятие позволяет описать, какими языками и в каком возрасте овладел человек, роль языков в его когнитивном и эмоциональном опыте и специфику этапов усвоения родного и неродного языков в аспекте онтогенеза (ранняя социализация, семья, школа, профессиональное становление) $[1 ; 4 ; 8 ; 14]$.

Речевая же биография - это «...изменения речевых привычек человека под воздействием социальных и профессиональных факторов в течение его активной сознательной жизни. Речевая биография должна включать в себя факты смены доминирующего речевого регистра, изменения просодических, фонетических и других характеристик речи в связи с изменением социального статуса, возраста, профессии, коллектива» [13, с. 226].

Важнейшим методом изучения языковой и речевой биографии является нарративное интервью, дополненное результатами наблюдений за речевым поведением личности и результатами экспериментальной работы с нею [1; 14].

Несмотря на различия, существующие между речевой и языковой биографиями индивидов, следует отметить, что оба этих понятия взаимосвязаны, поскольку факты языковой биографии человека влияют на его речевую деятельность.

Проводимое нами исследование, в целом, посвящено изучению особенностей языковой и речевой биографии пациентов (афатиков) с нарушением речи, которое возникает при органических поражениях мозга - афазиях. Это должно помочь в разработке упражнений по восстановлению речи у данных пациентов.

В рамках нашего исследования мы выделили целевые группы здоровых людей, попадающих в группу риска по афазиям, для их дальнейшего интервьюирования с целью моделирования вокабуля- 
ров, в определенной степени отражающих реальный ментальный лексикон групп риска, обусловленный их языковой и речевой биографией. Опора на такой частотный вокабуляр позволит нам разработать более персонализированный комплекс упражнений для реабилитации пациентов-афатиков.

Так, было проинтервьюировано 34 человека: 19 мужчин, со средним специальным образованием, рабочей профессией, средний возраст которых 52 года, и 15 женщин, в основном обслуживающий персонал, с высшим и средним специальным образованием, средний возраст которых 57 лет.

Используя метод структурированного интервью, мы включили в него три блока вопросов: сведения о респонденте, информация о его языковой и речевой биографии. Несколько вопросов, адресованных информантам, были сформулированы следующим образом: «Какие языки были распространены в родительском доме? Используете ли Вы данные языки? Можете ли Вы вспомнить какие-то фразы, приговорки, слышанные в детстве? Пользуетесь ли Вы сами ими сейчас во взрослой жизни?».

В ходе интервью было получено несколько интересных ответов, демонстрирующих то, как в результате переезда в другую страну или в другой регион у интервьюентов изменились их языковые компетенции, и, как следствие - речевые привычки:

1. Русский, русская школа. В школе ещё киргизский, потому что в Киргизии жили, но запомнилось несколько слов: "салам алейкум, бир-1, эки-2, счёт до 100, ата-отеи, эне-мама, нан - хлеб, кант - сахар», потому что на рынок ходил там, поэтому продукты знал и счет. Ищас знаю, но не пользуюсь, негде. (Геодезист, 80 лет).

2. Русский. Ну, у меня отеи родом с Белоруссии, он всегда вот такие слова говорил, как вот «ведро - цьбарка, картошкабульба, лук-иььбуля». Ну, иногда ия, да, ну не всегда, иногда, особенно после того, как мы в Сибирь приехали. (Делопроизводитель, 60 лет).

3. Русский. Ну, вот, в Сибири мы в семье говорили, допустим, слова «шоркать, вехотка, деда, баба, но», то сейчас, где 
мы живем, здесь так не говорят. С переездом на Запад, мы много где были, я, практически, перестала их употреблять, потому что меня не понимают. Спрашивали, что это такое, что за слово «шоркать» или «вехотка». Хотя в семье могу так сказать. (Документовед, 63 года).

4. Русский, конечно. Нет, ещеё украинский частично. Потому что мама и папа, все-таки, с Украины, и они - украинцыь. И они изредка говорили по-украински. Я просто, несколько, слов знаю, потому что уехала от них. Когда уехала, вообще, практически забыла. Вот их узнаю в речи, когда по телевизору говорят. Например, «хвиртка - калитка»,или, например, «криница - колодеиџ или «кохать - любить». (Учитель английского языка, 78 лет).

5. Русский, но мы несколько лет прожили в Молдавии. В первом классе изучала молдавский, но я его использую, несколько слов помню. Когда вспоминаю, что я его учила, то могу назвать хлеб - «пьйне», молоко-«лапте». (Социальный педагог, 35 лет).

6. Русский язык. Фразы, вот «чай» употреблялся везде у нас в Поволжье. Вредное слово такое. «Чай, чай». Даже, поговорка сложена: «Чай корова то пила, а брюхо то холодное». Вот это «чай» ко всем словам, ко всем предложениям у нас прибавлялся. Ну, щас мы его забыли, а раньше все время... Хотя иногда могу сказать. А, вообще, на Волге все окают, по-другому говорят. Но когда меня после техникума послали в Кемеровскую область, в город Калтан, я там пожила немножко, уже у меня разговор перешел на сибирский. По телефону, даже мать с отиом не узнавали, я же не по-ихнему стала разговаривать. Они как говорили на «о», так и говорят. Например, они не говорят «карова», а говорят «корова», «поила», «кровать». Там всёна «о», на «о». Любое слово и везде на «о». (Бухгалтер, 80 лет).

7. Русский и киргизский, мы в Казахстане жили. С казахского знаю «терезе-окно. Мектеп-икола. Хлеб-нан. Вода-су». (Слесарь, 55 лет). 
Таким образом, как видно по приведенным данным, в результате переезда у интервьюентов в значительной степени меняется языковая компетенция. Например, респондент забывает язык или перестает использовать такие слова, характерные для сибирского диалекта, как «вехотка, шоркать, деда, баба, но (вместо «да»)», или свойственные для Поволжья оканье и вводное слово «чай».

Как правило, основной причиной, почему у респондента происходит изменение языковых компетенций, является необходимость адаптироваться к новым языковым и речевым реалиям, поскольку на новом месте жительства говорят иначе, и нет необходимости в языке или диалекте, который человек употреблял до переезда. Результатом изменения языковой компетенции, как мы можем видеть, является формирование новых речевых привычек.

Однако, несмотря на данные изменения, респонденты не полностью утратили прежние языковые компетенции, поскольку они помнят некоторые слова из языка, на котором говорили в их родительском доме или в том месте, в котором они жили до переезда, а также особенности их прежних диалектов, и даже употребляют их иногда в речи. Как правило, это существительные, которые относятся к продуктам питания, терминам родства, предметам, необходимым в быту, к зданию и его частям.

Причину, почему интервьюенты запомнили исключительно эти категории слов, можно объяснить тем, что в ядре ментального лексикона концентрируются актуальные для человека образы действительности, а также житейские (обыденные) понятия, которыми он оперирует каждый день.

Кроме того, согласно Т.В. Ахутиной, в ядре ментального лексикона находятся первые значения, в качестве которых выступают комплексы образ-значение, являющиеся элементарными с точки зрения психолингвистической семантической сложности и приобретёнными еще в детстве [2].

Например, исследователи отмечают, что такие слова, как любить, ведро, картофель, колодец, окно, молоко, хлеб, упоминаемые нашими интервьюентами, усваиваются детьми в возрасте 1-2 лет [3]. 


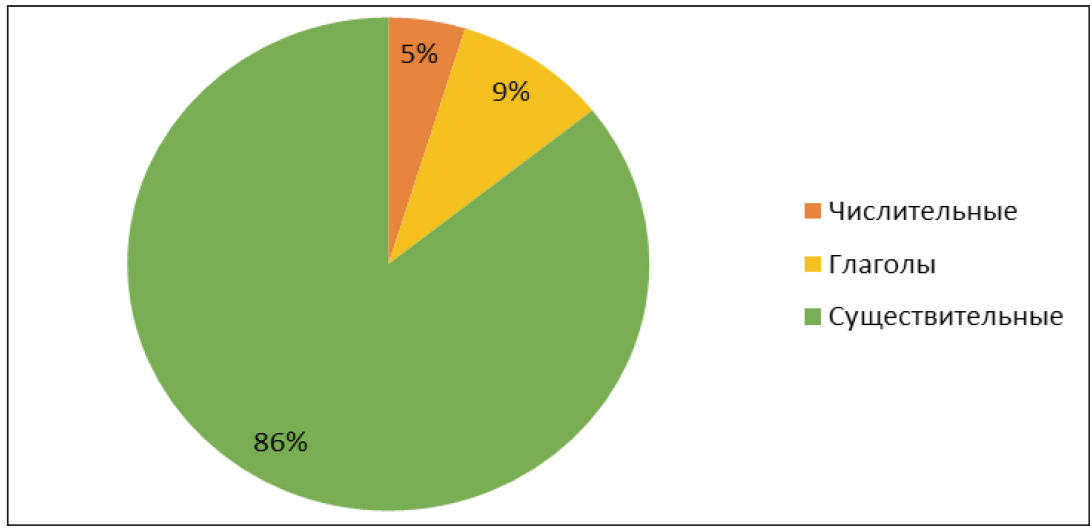

Диаграмма 1

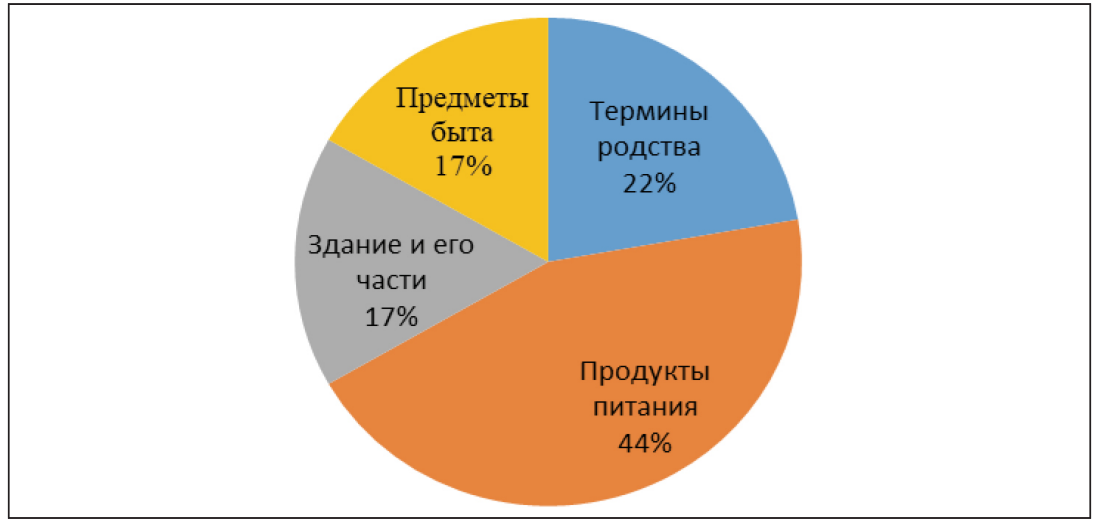

Диаграмма 2

Как утверждают наши респонденты, они также освоили вышеупомянутые категории слов, будучи детьми.

\section{Заключение}

Как мы видим, языковая и речевая биография является одним из факторов, влияющих на речевую продукцию человека (его языковую личность), а поскольку вербально-семантический уровень языковой личности представлен в ментальном лексиконе, то его структура и содержание также зависят от речевой и языковой биографии. 
Таким образом, знания языковой и речевой биографии помогают определить, какие слова могут находиться в ядре ментального лексикона.

В свою очередь, данный факт важно учитывать при реабилитации пациентов-афатиков, поскольку это дает возможность разработать для них индивидуальный комплекс упражнений, принимающий во внимание особенности их языковой личности и языковой / речевой биографии.

\section{Список литературы}

1. Александров О.А. Языковая биография немецких диалектоносителей с. Кожевниково Томской области // Вестник Красноярского государственного педагогического университета им. В.П. Астафьева. 2011. № 4 (18). С. 208-213.

2. Ахутина Т.В. Нейролингвистический анализ лексики, семантики и прагматики. М.: Языки славянской культуры, 2014. 423 с.

3. Библиотека стимулов. http://stimdb.ru/ (дата обращения: 05.02.2020).

4. Дебренн М. Языковая автобиография // Вестн. Новосиб. гос. ун-та, Серия: Психология. 2014. Т. 8, вып. 1. С. 55-64.

5. Залевская А.А. Проблемы организации внутреннего лексикона человека. Калинин. гос. ун-т, 1977. 83 с.

6. Залевская А.А. Введение в психолингвистику. М.: РГГУ, 1999. 566 с.

7. Золотова Н.О. Ядро ментального лексикона человека как естественный метаязык. Монография. Тверь: Лилия Принт, 2005. 204 с.

8. Иванов В.В. Лингвистика третьего тысячелетия: вопросы к будущему (главы 11-21). М.: Языки славянской культуры, 2004. 208 с.

9. Караулов Ю.Н. Русский язык и языковая личность. М.: Наука, 1987. $264 \mathrm{c}$.

10. Караулов Ю.Н. Русская языковая личность и задачи ее изучения // Язык и личность. М.: Наука, 1989. С. 3-8.

11. Китайгородская М.В., Розанова Н.Н. Русский речевой портрет // Фонохрестоматия. М.: Наука, 1995. 128 с.

12. Кубрякова Е.С. Язык и знание: На пути получения знаний о языке: Части речи с когнитивной точки зрения. Роль языка в познании мира. М.: Языки славянской культуры, 2004. 560 с. 
13. Лямзина С.А, Колмогорова А.В. Личность в зеркале языковой / речевой биографии // Филология: научные исследования. 2018. №4. С. 220-228.

14. Седов К.Ф. Дискурс и личность: эволюция коммуникативной компетенции. М.: Лабиринт, 2004. 317 с.

15. Терентий Л.М. Психолингвистическое изучение образа мира // Филологические науки. Вопросы теории и практики. 2018. №2 (80). С. 170-173.

\section{References}

1. Aleksandrov O.A. Yazykovaya biografiya nemetskikh dialektonositelej s. Kozhevnikovo Tomskoj oblasti [Language biography of German dialect carriers of Kozhevnikovo village, Tomsk region]. Vestnik Krasnoyarskogo gosudarstvennogo pedagogicheskogo universiteta im. V.P. Astaf'eva. 2011. № 4 (18), pp. 208-213.

2. Akhutina T.V. Neyrolingvisticheskiy analiz leksiki, semantiki i pragmatiki [Neuro-linguistic analysis of vocabulary, semantics and pragmatics]. M.: Yazyki slavyanskoy kul'tury, 2014. 423 p.

3. Biblioteka stimulov [An incentive library]. http://stimdb.ru/ (accessed February 5, 2020).

4. Debrenn M. Yazykovaya avtobiografiya [Language autobiography]. Vestn. Novosib. gos. un-ta, Seriya: Psikhologiya. 2014. № 1(8), pp. 55-64.

5. Zalevskaya A.A. Problemy organizatsii vnutrennego leksikona chelove$k a$ [Problems of organization of the person's internal lexicon]. Kalinin: Kalinin. gos. un-t, 1977. 83 p.

6. Zalevskaya A.A. Vvedenie v psikholingvistiku [Introduction to psycholinguistics]. M.: RGGU, 1999. 566 p.

7. Zolotova N.O. Yadro mental'nogo leksikona cheloveka kak estestvennyy metayazy [The core of the human mental lexicon as a natural metalanguage]. Tver, 2005. 204 p.

8. Ivanov V.V. Lingvistika tret'ego tysyacheletiya: voprosy $k$ budushhemu (glavy 11-21) [Linguistics of the Third Millennium: Questions for the Future (Chapters 11-21)]. M.: Jazyki slavjanskoj kul'tury, 2004. 208 p.

9. Karaulov Yu.N. Russkiy yazyk i yazykovaya lichnost' [The Russian language and language personality]. M.: Nauka, 1987. 264 p.

10. Karaulov Yu.N. Russkaya yazykovaya lichnost' i zadachi ee izucheniya [Russian language personality and the tasks of its study]. Yazyk $i$ lichnost' [Language and personality]. M.: Nauka, 1989, pp. 3-8. 
11. Kitaygorodskaya M.V., Rozanova N.N. Russkiy rechevoy portret [Russian speech portrait]. Fonokhrestomatiya [Phonohrestomaty]. M.: Nauka, $1995.128 \mathrm{p}$.

12. Kubryakova E.S. Yazyk i znanie: Na puti polucheniya znaniy o yazyke: Chasti rechi s kognitivnoy tochki zreniya [Language and knowledge: On the way of getting language knowledge: Parts of speech from a cognitive point of view]. Rol'yazyka v poznanii mira [The role of language in the knowledge of the world]. M.: Yazyki slavyanskoy kul'tury, 2004. 560 p.

13. Lyamzina S.A., Kolmogorova A.V. Lichnost' v zerkale yazykovoj / rechevoj biografii [Personality in the mirror of language / speech biography]. Filologiya: nauchnye issledovaniya. 2018. №4, pp. 220-228.

14. Sedov K.F. Diskurs i lichnost': ehvolyutsiya kommunikativnoj kompetentsii [Discourse and personality: the evolution of communicative competence]. M.: Labirint, 2004. 317 p.

15. Terentiy L.M. Psikholingvisticheskoe izuchenie obraza mira [Psycholinguistic study of the image of the world]. Filologicheskie nauki. Voprosy teorii i praktiki. 2018. №2 (80), pp. 170-173.

\section{ДАННЫЕ ОБ АВТОРЕ}

Лямзина Светлана Алексеевна, аспирант кафедры романских языков и прикладной лингвистики, Институт Филологии и Языковой Коммуникации

Сибирский Федеральный Университет

пр-т Свободный, 82A, г. Красноярск, 660041, Российская Федерачия

svetlana.lyamzin@mail.ru

\section{DATA ABOUT THE AUTHOR}

Lyamzina Svetlana Alekseevna, Post-graduate student, Department of Romance Languages and Applied Linguistics, Institute of Philology and Language Communication

Siberian Federal University 82A, Svobodny pr., Krasnoyarsk, 660041, Russian Federation svetlana.lyamzin@mail.ru

ORCID: 0000-0002-7046-2871 